\title{
ESCOLA-DE-FERRO: UM TREM (DES)GOVERNADO PELO SENTIMENTO
}

\author{
RODRIGO DA SILVA GOMES*
}

\section{RESUMO}

O presente estudo pretende possibilitar um diálogo entre a poesia de Adélia Prado (1935) e a filosofia de Emmanuel Lévinas (1905 - 1995) com o propósito de permear novas vias para as relações constituídas pelos processos educacionais. Nesse sentido, cabe perceber o quanto das inquietações adelianas diante do cotidiano e de suas relações metafóricas estão expostas, por meio da linguagem e proporcionam novos caminhos capazes de potencializar as aprendizagens entre educadores e educandos e mediarem suas relações pela alteridade. Tal conceito filosófico trabalhado por Lévinas sugere, neste contexto, que as relações intrínsecas aos processos de ensino-aprendizagem componhamse de poesia e filosofia para uma educação baseada no diálogo, na valorização e na ética da responsabilidade com o Outro. Mesmo que a filosofia de Lévinas ou a poesia de Adélia não sejam construções voltadas especificamente para a educação e/ ou para uma pedagogia educacional, suas reflexões não excluem as capacidades e interações necessárias para metodologias que concebam instrumentos possíveis para consagrarem as diversidades presentes no cotidiano escolar. Nessa direção, a busca por sentidos que concedam ao acolhimento do Outro no âmbito educacional, reconhecendo e afirmando os sujeitos nas diferenças, tendem ao sentido maior das formas capazes

* Mestre em Educação pela Universidade Metodista de São Paulo com a dissertação: Escola-de-ferro: um trem (des)governado pela "Reforma do Ensino Médio”, orientada pelo Prof. Dr. Marcelo Furlin. 
de emergirem em possíveis diretrizes mediadoras entre ensino e aprendizagem, transfigurando-se em um sistema aberto, inconcluso e complexo.

Palavras-chave: Adélia Prado, Emmanuel Lévinas, Reforma do Ensino Médio.

\section{ABSTRACT}

The present study intends to make possible a dialogue between the poetry of Adélia Prado (1935) and the philosophy of Emmanuel Lévinas (1905-1995) with the purpose of permeating new routes for the relations constituted by educational processes. In this sense, it is important to realize how much the anxieties about everyday life and its metaphorical relations are exposed through language and provide new ways of enhancing the learning between educators and learners and mediate their relations for otherness. Such a philosophical concept worked by Lévinas suggests in this context that the relations intrinsic to the teaching-learning processes are composed of poetry and philosophy for an education based on dialogue, valorization and the ethics of responsibility with the Other. Even if Lévinas' philosophy or Adélia's poetry is not constructions specifically geared to education and / or educational pedagogy, his reflections do not exclude the capacities and interactions necessary for methodologies that devise possible instruments for consecrating the diversity present in the school daily life. In this direction, the search for senses that grant to the reception of the Other in the educational sphere, recognizing and affirming the subjects in the differences, tend to the greater sense of the forms able to emerge in possible mediating directives between teaching and learning, being transfigured in an open system, unfinished and complex. Keywords: Adélia Prado, Emmanuel Lévinas, Reforma do Ensino Médio.

\section{INTRODUÇÃO}

Ao se pensar em uma investigação voltada para as transformações das relações educacionais tradicionais partese, inicialmente, do propósito de contribuir com os processos 
de ensino-aprendizagem que, por conta dessas experiências individuais, acabam parecendo necessárias e imprescindíveis. Entretanto, o estudo que se seguirá, por também se tratar de um tecido debruçado sob a poesia de Adélia Prado, tomará as devidas precauções para não ficar imerso na concreteza $a^{1}$ de amarras metodológicas e científicas que podem cercear a originalidade, a espontaneidade e as pretensões diante de seus percursos, mesmo que tais provocações adelianas já se constituam como poderosos aspectos para impossibilitar tais amarras.

Tentando "explicar a poesia sem ninguém pedir", Adélia nos possibilita criar e brincar a partir da construção metafórica do texto. Assim, a instituição educacional constituída no século $\mathrm{XVIII}^{2}$ e que parece perdurar até os tempos atuais, hora tentando se reinventar aqui, hora ali, traz consigo, muitas vezes, estruturas rígidas em sua concepção ideológica e funcional. Em muitos momentos cheirando ferrugem e trilhando por séculos as mesmas linhas que transportam e formatam cargas de maneira exaustiva, diante de caminhos quase sempre sem volta ou alternativas que possam transcender em direções diversas para além das possibilidades mecânicas, metódicas e quadradas que, ao que parece, tornaram-se regras do contexto escolar.

Ao pensar em uma proposta que se mostre dinâmica e que, de alguma forma, interfira de maneira prática nas relações entre os atores sociais que se encontram presentes nessa parte institucional de formação cidadã a que se propõe a escola, um tecido pautado pelo cotidiano, teremos como interlocutores, além das poesias de Adélia Prado, a filosofia de Emmanuel Lévinas, tentando estabelecer uma relação que contemple a ética e a responsabilidade constituída tanto por professores, quanto por alunos. Assim, entendemos que sua conceituação sobre a

1 O termo utilizado faz referência a um trecho do livro de prosa de Adélia, Solte os cachorros (1979): "eu acho fascinante a concreteza do mundo, a massa compacta e fumegante do angu" (p. 78).

2 Aqui, trata-se do modelo de escola construído ao longo dos processos das revoluções surgidas na Europa, diretamente influenciadas pelo Iluminismo e pelas concepções de uma escola voltada para o ensinamento de valores e condutas sociais básicas. 
alteridade possa, de fato, estabelecer laços de compreensão e, mais do que isso, construir possibilidades para uma espécie de humanismo educacional, muitas vezes abafado ou perdido entre burocracias, estatísticas, metas e afins, que facilmente podem criar um distanciamento entre os atores escolares.

Em Lévinas, que sugere a ética como filosofia primeira, podemos vislumbrar nossa capacidade de transcender enquanto educadores e educandos, fazendo assim com que nossas relações com o Outro se manifestem em respeito, responsabilidade, possibilidades e, consequentemente, em novas concepções sobre ensino-aprendizagens. Nisso, a relação ser/objeto tende a exprimir, por meio da linguagem e também do corpo, os subsídios que transfiguram os papeis encarnados entre as palavras e as coisas. Propõe ele:

É evidente, por consequência, que a linguagem, pela qual a significação se produz no ser, é uma linguagem falada por espíritos encarnados. A encarnação do pensamento não é um acidente que lhe teria acontecido e que viria gravarlhe a tarefa, desviando de sua retidão o movimento reto pelo qual o pensamento visa ao objeto. O corpo é o fato de que pensamento mergulha no mundo que pensa e que, por consequência, exprime este mundo ao mesmo tempo que o pensa. O gesto corporal não é descarga nervosa, mas celebração do mundo, poesia. (LÉVINAS, 2012, p. 30).

Ainda que Lévinas não trate especificamente sobre o contexto educacional, mas apresente uma análise fenomenológica, ou seja, uma atitude reflexiva dos fenômenos observados por nós na relação que estabelecemos com os outros, no mundo, pode-se pensar o quanto dessa análise pode servir para a formação de educadores no trato direto entre conteúdo disciplinar e interação entre conhecimentos e práticas educacionais, tendo no contato com o Outro a abertura necessária para transformações das circunstâncias. Assim, pode-se afirmar, nos aspectos educacionais que aqui se pretendem debater, que em Lévinas podemos identificar uma filosofia na qual, se 
inserida especificamente no campo da educação, uma intensa relação de ensino-aprendizagem encarnada e "compreender que nossa situação no real não é defini-la, mas encontrar-se numa disposição afetiva; compreender o ser é existir." (LÉVINAS, 2010, p. 23).

Há que se entender que o trilho pelo qual nosso trem percorre seu caminho é metaforizado como sendo o paradigma tradicional - sempre presente - estruturado de maneira que sirva como um suporte fixo e linear de sustentação, enquanto que o paradigma educacional emergente, ou as abordagens que se seguem, adiciona curvas que alternam tal caminho. Contudo, um não exclui o outro, nem se anulam completamente entre si, sendo complementares à medida que se apresentem as circunstâncias do cotidiano. Assim, quando pensamos na alteridade com a intermediação e facilitação da poesia não fazemos uma alusão a qualquer tipo de desconstrução do trilho educacional, mas sim em uma espécie de instrumento que esteja presente entre os paradigmas educacionais e as relações intersubjetivas que ocorrem nos vagões da escola. A alteridade, portanto, teria a função de atenuar o atrito causado entre o contato dos trilhos com o trem e também de facilitar as construções dos conhecimentos, permitindo experienciar os conceitos abstratos tratados na escola por meio dos sentidos estabelecidos e vivenciados com o Outro.

\section{A ESCOLA COMO PARTE DO TODO}

Da filosofia, mais especificamente da filosofia de Platão e dos gregos antigos ${ }^{3}$, podemos absorver o conceito que deu origem ao termo moderno de escola. Scholé, que posteriormente foi traduzida para o latim como Otium (ócio ${ }^{4}$ ), é, segundo as

3 Não nos cabe querer formatar nossa educação contemporânea aos moldes do mundo grego antigo. Sabemos que os tempos são outros, com novas estruturas sociais, diferentes maneiras de concebermos a vida e novas concepções da realidade do século XXI. O trecho serve apenas como recurso didático de comparação.

4 Interessante notar que a origem da palavra ócio está relacionada como uma forma de trabalho, de ser e de agir no mundo, e não como é usada na contemporaneidade ("não fazer nada", "preguiça” ou "indolência"). 
considerações platônicas, o local do labor livre, do lazer, do brincar, do momento válido por ele mesmo, potencializando a vocação do ser em sua totalidade para si e para os outros. Em contraposição ao conceito de negócio, negador do ócio ${ }^{5}$ que, no contexto moderno, privilegia as relações particulares de situações que anseiam resoluções práticas e úteis para uma determinada finalidade que pode terminar em si mesma.

A vinculação ideológica entre educação e os aspectos ligados às necessidades cotidianas dos indivíduos (comer, vestir, morar, etc) faz parte de uma significação que Lévinas chamará de "econômica". Segundo ele, "a significação fixa, privilegiada, que o mundo adquire em função das necessidades do homem, opõe-se, de fato, à multiplicidade de significações que afluem à realidade a partir da cultura e das culturas" (LÉVINAS, 2012, p. 36). A interação entre as necessidades básicas dos indivíduos em "significações econômicas" tende a orientar as significações e os sentidos dos aspectos culturais que estão para além desta. Sabemos, entretanto, que Lévinas não está tratando especificamente das questões econômicas no sentido financeiro do termo, dessa maneira, entendemos ser necessário trazer para a discussão uma interação prática das questões que relacionam educação e capital.

Embora o constructo social como um todo anseie para que educação seja a salvação para todos os problemas sociais que estamos acostumados a observar e também a participar, a intenção aqui não é essa. Entendemos a importância da educação e dos processos de ensino-aprendizagens, contudo não podemos manter uma postura ingênua diante do movimento sistêmico que já foi observado aqui, com todas as implicações que a sociedade exerce sobre tais processos educacionais. Mas nos

\footnotetext{
Para Platão, o ócio era o princípio da Filosofia em conexão com a verdade e a liberdade. Só pode dedicar-se a filosofar quem tem tempo para isso. Aristóteles definiu a relação entre ócio e negócio assim: "Somos ativos a fim de ter ócio", mostrando que o ócio é um fim em si mesmo. $\mathrm{Na}$ Modernidade isso foi renegado, porque o conhecimento já não é produzido no ócio, mas no processo produtivo. O conhecimento não é mais contemplativo, mas quer dominar a natureza, vencê-la, explorá-la, adaptá-la às necessidades da humanidade.
} 
cabe intencionar novas maneiras para que as relações perceptíveis entre educadores e educandos, além, é claro, das interferências externas à sala de aula - gestores, diretores, coordenadores, etc - estejam dispostas de maneiras a constituírem-se de maneiras menos mecânicas, abstratas e conceituais, e mais ecológicas ${ }^{6}$, e que se manifestem claramente os movimentos intrínsecos à compreensão do todo em conjunto com as partes em movimentos que dialoguem entre si e para si.

As partes que compõem as estruturas rígidas na construção desse trem de ferro, dessa objetivação coisificada composta por parafusos, fluidos, ferro, engrenagens, etc., que materializa a totalidade do trem em si, estão dispostas de forma em que o resultado seja o mais próximo possível da homogeneização e da compactação do material que esse carrega, entretanto se configuram de maneira desconexa entre o todo, tentando fazer com que quase não haja diálogo, tampouco movimento constante entre os vagões. A flexibilização precoce, já possibilitada no "novo" ensino médio, por exemplo, pode potencializar o distanciamento entre os conhecimentos, além de privilegiar aspectos que vão de encontro ao conceito central existente nos modelos emergentes de paradigma educacional e humanístico, podendo fazer das áreas do conhecimento uma reprodução linear de uma visão ideológica da realidade.

\section{O RECONHECIMENTO MÚTUO NO ENSINO-APRENDIZAGEM}

Os mecanismos metodológicos de muitas instituições de ensino regulares, como já destacados até aqui, podem estabelecer distanciamentos entre os agentes sociais circunscritos nas relações de ensino-aprendizagem. Diretores, educadores, coordenadores e educandos constituem, muitas vezes, organismos separados e independentes, havendo nessas

\footnotetext{
6 O termo "ecológicas" faz referência ao conceito de Boaventura de Souza Santos. Ele defende a ideia de que cada saber existe apenas em meio a outros saberes, e nenhum é capaz de se bastar, sempre existe a necessidade de fazer referência a outros saberes. A comparação é inevitável à exploração dos próprios saberes, a seus limites e possibilidades.
} 
relações modelos pertinentes que subjugam os diferentes aspectos intrínsecos aos indivíduos conduzindo os métodos de ensino e de aprendizagem para representações potencialmente doutrinadoras, as quais tornam as significações com o Outro instrumentos totalitários e passíveis de domesticação.

Os avanços e os aprimoramentos do sistema econômico vigente são capazes, continuamente, dentre outras coisas, de replicar suas condutas éticas das relações de trabalho para o ambiente escolar, transformando as relações de ensinoaprendizagem em técnicas para a sua própria reprodução. Em suma, as formas técnicas baseadas na racionalidade das operações para o trabalho útil possibilitam, em grande medida, para que a educação e suas etapas para o conhecimento e para as relações entre seus agentes se configurem em um afastamento das questões éticas que possibilitem críticas acerca da educação tradicional, ou mesmo qualquer forma de educação que se vislumbre de maneira livre, espontânea e ética. Entretanto, não se trata aqui de uma recusa simplista sobre a imposição da razão ou uma dicotomia metafísica da subjetividade que conteste a fenomenologia das relações por si só, mas sim uma interação entre as variadas contemplações poéticas acerca do cotidiano e uma busca por uma conduta ético-filosófica que preserve aspectos que excedam a ideia de uma ontologia da alteridade para se pensar o desenvolvimento com um sentido (ou mesmo com um sentimento) humanista para as relações de ensinoaprendizagem nas instituições educacionais regulares.

Nessa percepção em conjunto, poetiza Adélia sobre o querer do outro, em Poema começado do fim:

Um corpo quer outro corpo.

Uma alma quer outra alma e seu corpo.

Este excesso de realidade me confunde.

Jonathan falando:

parece que estou num filme

Se eu lhe dissesse você é estúpido

ele diria sou mesmo. 
Se ele dissesse vamos comigo ao inferno passear eu iria.

(PRADO, 2015, p. 298)

Adélia versa sobre o cotidiano da vida, sobre as sensações e as experiências capitadas por suas observações das experiências habituais e corriqueiras que muitas vezes passam despercebidas, ou passam sem serem contempladas, diante de olhos não poéticos. Entre sua capacidade de desenvolver uma espécie de autobiografia, possibilita também uma interação peculiar entre os aspectos que se dão por meio do contato e do apego ao Outro, pois "quando o que um corpo deseja é outro corpo para escavar" (PRADO, 2015, p. 110), transbordando em sua linguagem.

Em vias poéticas, Adélia dialoga a todo instante com o Outro, em uma relação provocativa que se manifesta na intenção e no desejo de pertencimento diante das características que se alteram e se expressam como ser/estar no mundo. Diante disso, a alteridade que se configura como fio condutor entre suas concepções reveladas pelo olhar poético da vida, anunciando o Outro como pressuposto para afirmar a si própria como definição dessas relações inter-relacionadas no mundo, funciona como elemento de reconhecimento do próprio eu-lírico.

Tendo o saber como "a relação do homem com a exterioridade, a relação do Mesmo com o Outro, em que o Outro se encontra finalmente, despojado de sua alteridade, se faz interior ao meu saber e sua transcendência se faz imanência" (LÉVINAS, 2010, p. 206) e tomando como suporte o conceito de alteridade em Lévinas, que aborda a proposição de se relacionar e conviver sob a constância permanente da ética perante o próximo, permitindo alcançar novas etapas para um entendimento e uma formação mais humana diante das integrações, as concepções de mundo que se abrem e se permitem diante de si, externa e internamente, consagram as experiências como consumidoras do Outro. Assim esclarece Lévinas sobre como se dá a manifestação e a significação do Outro diante de nossas percepções:

A manifestação do Outro produz-se, certamente, à primeira vista, de acordo com o modo pelo qual toda significação se 
produz. O Outro está presente numa conjuntura cultural e dela recebe sua luz, como um texto do seu contexto. A manifestação do conjunto assegura sua presença. Ela aclara-se pela luz do mundo. A compreensão do Outro é, assim, uma hermenêutica, uma exegese. O Outro dá-se no concreto da totalidade à qual é imanente e que, conforme as análises notáveis de MerleauPonty, que nós utilizamos largamente nas primeiras seções deste trabalho, nossa iniciativa cultural - o gesto corporal, linguístico ou artístico - exprime e desvela. (LÉVINAS, 2012, p. 50).

A concepção do Outro passa, necessariamente, pela imbricação do Eu. No contexto educacional do qual estamos tratando nesta pesquisa, a concepção que o educador faz do educando está, inevitavelmente, em si-mesmo. De uma maneira didática, a noção do Eu diante dos aspectos da linguagem e das significações para distinguir os traços pertinentes entre os educadores e educandos em um processo dialógico de ensinoaprendizagem, em suas intermitentes negações e afirmações perante as relações construídas no ambiente escolar, pode estar relacionada com essa noção de negação e afirmação entre as relações pautadas pela necessidade de compreensão por meio da reciprocidade. Reciprocidade essa que se pode estabelecer com o elo entre a poética de Adélia e a filosofia ética de Lévinas em um possível reconhecimento mútuo entre educador e educando.

$\mathrm{Na}$ presença dessa concepção entre linguagem e significação, o aspecto do sentido por meio do corpo está presente na construção da percepção de si-mesmo e também do Outro. Segundo Lévinas, "o gesto corporal não é descarga nervosa, mas celebração do mundo, poesia”. Ainda:

O corpo é um sensor sentido. (...) Ele une a subjetividade do perceber (intencionalidade visando ao objeto) e a objetividade do exprimir (operação no mundo percebido que cria seres culturais - linguagem, poema, quadro, sinfonia, dança clareando os horizontes). A criação cultural não se acrescente à receptividade, mas é imediatamente sua outra face. Nós não somos sujeito do mundo e parte do mundo de dois pontos de vista diferentes, mas, na expressão, nós somos sujeito e parte ao 
mesmo tempo. Perceber é, ao mesmo tempo, receber e exprimir, por uma espécie de prolepse. (LÉVINAS, 2012, p. 30).

As especificações entre as relações com o Outro permeiam os patamares do reconhecimento (também de si-mesmo) perante a percepção das diferenças. Ricoeur (2006) traz em sua concepção sobre o reconhecimento mútuo a ênfase entre identidade pessoal e comunitária. Existe, para ele, a distinção entre reconhecer e ser reconhecido em que tal distinção definiria as condutas sociais e particulares diante do reconhecimento do indivíduo pelo Outro.

O reconhecimento de si é o princípio que possibilita o reconhecimento político do Outro no contexto social capaz de o indivíduo reconhecer seus atos a partir de uma sabedoria prática e perceber-se como sujeito no mundo. Sujeito este que estabelece relações com outros indivíduos, cada um com suas aspirações e concepções de sujeitos de si. Tais relações, por conterem um caráter fenomenológico das práticas individuais e sociais, acabam por gerar os conflitos sociais que sempre estarão presentes, pois se tratam, antes, de um conflito particular e individual, que é concebido no reconhecimento ou não dos pares que estão fazendo parte do jogo social. As formas de interpretação as quais os sujeitos estão condicionados são condições pré-concebidas de análises e decisões que influenciam e conduzem os atos individuais nas possibilidades construídas particularmente, principalmente num aspecto econômico por conta da não equidade na distribuição dos bens sociais.

Tem-se, portanto, nos processos de ensino-aprendizagens, a necessidade primeira de haver um reconhecimento de si como educador-educando e um reconhecimento do Outro como educando-educador, tentando, por essas vias, construir laços de amor, amizade e fraternidade para que se possibilitem aproximações e distanciamentos justos entre os indivíduos a fim de conceberem um sentido de justiça social na aprendizagem pautada pela cooperação mútua.

Lévinas concentra seus argumentos nas estruturas as quais ele julga deficientes no método fenomenológico. Em sua concepção, quando a experimentação do fenômeno se depara 
com o Outro, estabelece-se aí um problema. Segundo ele, a fenomenologia se ocupa das experimentações do sujeito que, por meio da reflexão, é capaz de vivenciar de forma direta ou imediata à suas "próprias experiências". Mas como experienciar a consciência do Outro? Tal experiência estaria disponível para mim? Lévinas tentará responder a estas questões orientado por uma filosofia ética e não epistemológica das estruturas de relações entre o sujeito e o Outro. Assim:

Esta inversão humana do em-si e do para-si, do "cada um por si”, em um eu ético, em prioridade do para-outro, esta substituição ao para si da obstinação ontológica de um eu doravante decerto único, mas único por sua eleição a uma responsabilidade pelo outro homem - irrecusável e incessível esta reviravolta radical produzir-se-ia no que chamo encontro do rosto de outrem. Por trás da postura que ele toma - ou que suporta - em seu aparecer, ele me chama e me ordena do fundo de sua nudez sem defesa, de sua miséria, de sua mortalidade. É na relação pessoal, do eu ao outro, que o "acontecimento" ético, caridade e misericórdia, generosidade e obediência, conduz além ou eleva acima do ser. (LÉVINAS, 2010, p. 242).

Tal ética da responsabilidade para e com o Outro se caracteriza pela absorção absoluta da diferença experimentada nas relações entre os sujeitos. Uma vez que não se pode alcançar a totalidade da apreciação nas experiências fenomenológicas com o Outro por conta da separação entre um e outro, cabe agora a tentativa de se alcançar a responsabilidade de não se transgredir ou infringir tal separação. No discurso, “a estrutura formal da linguagem anuncia a inviolabilidade ética do Outro e, sem qualquer vestígio do "numinoso", "sua" santidade." (LÉVINAS, 1980, p. 195).

Nas estruturas que modelam as relações ensinoaprendizagem, ao longo da construção das especificidades modernas e racionalistas, as capacidades inerentes aos conceitos de desenvolvimento educacional e experimental no Ocidente sempre se deram mediante a totalidade e sobre o poder do Mesmo. Diante disso, a poesia adeliana se torna um viés de perceptividades, impossibilitando a construção de um ser 
totalitário que se reconhece em si próprio mediante as relações estabelecidas com o Outro. Nota-se que mesmo promovendo e exaltando a figura divina de Deus e suas características sagradas, Adélia se constrói nessa capacidade de reconhecer a diferença e as várias formas e manifestações que são possíveis de absorção de responsabilidade e acolhimento ético.

Em princípio, uma leitura rasteira e despretensiosa dos poemas de Adélia e de sua relação com o sagrado pode favorecer uma observação em que o Outro fique suspenso e privado de conservar-se em sua alteridade, fazendo parte de um sistema total (Deus) que dita todas as regras, não concebendo espaço nem tampouco maneiras de agir, entretanto, em uma visita mais perspicaz e intimista diante da exposição das poesias adelianas com o divino, pode-se perceber que é justamente nestas relações que Adélia constrói suas vivências e, em suma, constrói seu próprio ser. Em Linhagem, ela nos permite perceber os Outros que a permitiram:

Minha árvore ginecológica

me transmitiu fidalguias, gestos marmorizáveis:

meu pai, no dia do seu próprio casamento, largou minha mãe sozinha e foi pro baile.

Minha mãe tinha um vestido só, mas

que porte, que pernas, que meias de seda mereceu!

Meu avô paterno negociava com tomates verdes, não deu certo. Derrubou mato pra fazer carvão, até o fim de sua vida, os poros pretos de cinza: 'Não me enterrem na Jaguara. Na Jaguara, não.' Meu avô materno teve um pequeno armazém, uma pedra no rim, sentiu cólica e frio em demasia, no cofre de pau guardava queijo e moedas.

(PRADO, 2016, p. 107). 
Adélia, por meio dessas frases, exala as dimensões que o Outro pode nos permitir e que nós, semelhantemente admirados, permitimos em uma medida parecida e diante de anseios parecidos. A percepção de que transmitimos os sentimentos construídos em comunhão diante da relevância dos que também constroem nossas maneiras de absorver as relações sentidas pode possibilitar o entendimento que educadores e, em simetria, a própria noção de escola e do processo de ensino-aprendizagem constituam-se diante dos educandos de maneiras demasiadamente interdependentes e vinculadas.

\section{A ALTERIDADE COMO APRENDIZAGEM PRIMEIRA}

Até o momento, a escola, como a percebemos atualmente, trilha seu caminho a todo vapor em consonância e pelos caminhos estabelecidos em conjunto com o aprimoramento da sociedade capitalista e suas nuances, contradições e contrapontos. Assim, sendo uma parte de um todo em incessante construção, a ideologia que permeia o ambiente escolar do século XXI corre o risco de possuir a capacidade intrínseca de estabelecer e (re) produzir as aspirações advindas com o pensamento dominante da individualização, do privilégio do sujeito, ou seja, da onipotência do Eu que se apresenta como um paradigma em que o ego está acima de todas as relações percebidas, conduzindo um modus operandi de sociedade em que o Outro está em um horizonte distante, havendo um abismo entre o sujeito - o Eu - e esse Outro. Tal privilégio que vêm ditando as normas das relações sociais - culturais, econômicas e políticas - e têm se mostrado como uma das causas desse distanciamento entre os sujeitos nas sociedades modernas ocidentais, coloca como fundamento a exacerbação de uma civilização em que o individualismo é caracterizado pelo si-mesmo em detrimento do Outro. Um si-mesmo que, pleno de sua existência no mundo - com seu modo de ser, pensar, produzir e reproduzir o mundo - pouco é responsável pelo Outro como um sujeito pleno e também imbuído de subjetividades próprias. 
Lévinas (1980) coloca a ética como filosofia primeira. Assim, do mesmo modo podemos vislumbrar a alteridade como aprendizagem primeira, insistindo que nas relações de ensino-aprendizagem constituídas e em constante e permanente movimento na escola, independentemente de políticas públicas que afastem, ou no mínimo não privilegiem a percepção do Outro como fundamento de construção do saber em conjunto, os atores envolvidos - educador e educando - estejam dispostos para além de quaisquer tipos de abordagens nesse processo. Assim, construindo sua crítica sobre a filosofia ocidental, em que, segundo ele, "o ser exime-se de sua alteridade:

A filosofia se produz como uma forma sob a qual se manifesta a recusa do engajamento no Outro, a espera em detrimento da ação, a indiferença com relação aos outros, alergia universal da primeira infância dos filósofos. O itinerário da filosofia continua sendo o de Ulisses, cuja aventura no mundo não passou de um retorno à sua terra natal - uma complacência no Mesmo, um desconhecimento do Outro. (LÉVINAS, 2012, p.43).

Ao dialogar com os gregos antigos e buscar o sentido do ser, sua ontologia, Lévinas esforça-se em apresentar que tal linguagem como portadora de sentidos fenomenológicos está mais diretamente fundamentada na supremacia da razão. Nesse aspecto, criticando a história do pensamento filosófico ocidental moderno e suas categorias tais como tempo, existência, liberdade, etc, Lévinas dedica maior atenção para a questão da totalidade ${ }^{7}$.

O filósofo propõe como ética a prioridade para o Outro buscando mudar o paradigma moderno - ao qual a escola, consequentemente, está inserida - em que a existência do Outro depende da permissão do Eu. Esse indivíduo em-si-mesmado, que tem a percepção de si em posição de superioridade aos

Segundo Lévinas, toda a racionalidade ocidental está remetida a totalidade. Tal categoria é a expressão mais contundente do que se tornou a filosofia ocidental, em um empenho de totalização no qual apresenta-se como uma filosofia da violência, do poder e da injustiça (LÉVINAS, 1980). 
demais, principalmente aos demais que não estão inseridos no mesmo patamar de classificação enunciado por ele mesmo. Seria, como exemplo desse caso, um processo educacional no qual o educador está em existência e em permanente processo de afirmação de si mesmo e não em conjunto com os educandos.

A filosofia ocidental, na concepção de Lévinas, possui em si a pretensão de totalidade ontológica. Também por meio disso, cria-se um obstáculo para a alteridade e a percepção do Outro. Segundo ele, essa filosofia ocidental - que parte dos gregos antigos - pautada na competição e na individualidade, torna-se uma filosofia egoísta, voltada para o próprio ser-em-si-mesmo. Em suas palavras:

O primado do Mesmo foi a lição de Sócrates: nada receber de Outrem a não ser o que já está em mim, como se, desde toda a eternidade, eu já possuísse o que me venha de fora. Nada receber ou ser livre. A liberdade não se assemelha à caprichosa espontaneidade do livre arbítrio. O seu sentido último tem a ver com a permanência no Mesmo, que é a Razão. O conhecimento é o desdobramento dessa identidade, é liberdade. O fato de a razão ser no fim de contas a manifestação de uma liberdade, neutralizando o outro e englobando-o, não pode surpreender, a partir do momento em que se disse que a razão soberana apenas se conhece a si própria, que nada mais a limita. A neutralização do Outro, que se torna tema ou objeto - que aparece, isto é, se coloca na claridade - é precisamente a sua redução ao Mesmo. (LÉVINAS, 1980, p. 31).

Sob um contexto educacional, consequentemente pautado pelo princípio ocidental do retorno a si-mesmo, pode-se construir possibilidades e inter-relações que aproximem o simesmo do Outro por meio das sensações, assim, a aprendizagem pode ser percebida por meio de três sensações. A sensação do corpo (da matéria), da alma (que anima a matéria e a (in) consciência) e do espírito (que é a (in)consciência da matéria, animada também pela alma). A sensação do corpo próprio 
e do corpo do Outro pode ser perceptível por meio dos sentidos, assim como a sensação da alma (própria e do Outro). Entretanto, a sensação da (in) consciência do Outro ficaria menos perceptível se não fosse a linguagem. A linguagem, talvez, seja a maior responsável por fazer com que tenhamos um pouco mais de percepção sobre a (in) consciência do Outro. Assim, o educador percebe o mundo na materialidade das coisas. Percebe, de maneiras distintas, a sala de aula, o diário de classe, as tecnologias envolvidas nesse processo, o currículo, a configuração física dos educandos, etc, tudo na matéria, no físico. E essa percepção não pode ser individualizada, voltada e fechada em si mesma. Ela pode ser construída e alimentada permanentemente pelas percepções que esse educador estabelece em conjunto, em comunhão com o Outro, no caso os educandos. Sem o Outro não se percebe nada. Sem o Outro, o educador não sente o processo de ensino-aprendizagem em sua plenitude do possível com todas as nuances em que o processo estabeleça-se como um conjunto de sentidos, sentimentos, conceituações e interações permanentes. "A condição humana é corporal. O mundo só se dá sob a forma do sensível. Não há nada no espírito que em primeiro lugar não se tenha hospedado nos sentido" (LE BRETON, 2016, p. 24). Primeiramente, sentimos o vento para depois conceitua-lo racionalmente. A escola, ao que parece, sem compromissos com os sentidos, apenas conceitua sobre o vento por meio de abstrações inerentes aos seus compromissos sociais.

Pressupõe-se que o ambiente escolar seja o local das certezas positivas e do esclarecimento. Pressupõe-se também que as estruturas que sustentam as habilidades constatadas em uma avaliação, por exemplo, estejam em constante diálogo com o exterior, preparando cidadãos capacitados para usufruir de uma vida para o mundo e com o mundo. Cabe nos questionarmos se de fato as ambições educacionais conseguem atingir a universalidade das coisas, ou como pretende esta pesquisa, abrir caminhos para possibilidades que concedam apreender o mundo nas relações e nas constatações cotidianas.

Adélia, tratando de admirar-se pelo cotidiano, tece: 
(...)

Frigoríficos são horríveis

mas devo poetizá-los

para que nada escape à redenção:

Frigorifico do Jiboia

Carne fresca

Preço joia.

(...)

(PRADO, 2015, p. 246).

Ao poetizar os frigoríficos, ambientes do cotidiano que sugerem utilidade para o mundo do trabalho, assim como bancos, supermercados, lavanderias, e também nos mesmos moldes da Tabacaria de Fernando Pessoa ${ }^{8}$, Adélia parece sustentar a necessidade de encantar-se e admirar-se com este mesmo cotidiano que nos cerca a todo instante e que não nos desperta mais significações além das utilidades banais da vida comum. Mesmo em Lévinas "a possibilidade de um pensamento é a consciência do milagre ou a admiração" (LÉVINAS, 2010, p. 36).

A transcendência poética que pode expor o cotidiano por meio da linguagem de Adélia, presumindo a exaltação da vida em sua magnitude momentânea e ocasional que, muitas vezes, pode passar despercebida diante das manifestações construídas pelo mundo do trabalho e das utilidades comuns parece contribuir para que as percepções das relações entre educadores e educandos nos processos de ensino-aprendizagens estejam dispostas nas constituições das sensações e dos sentidos experimentados enquanto momentos e vivências que manifestamse, antes de conceitos abstratos, em signos e significados percebidos pelos sentimentos. Vejamos as preposições no trecho de um poema adeliano chamado "Leituras":

8 Em Tabacaria, Pessoa sugere as distinções entre as ações funcionais do mundo, da vida utilitária, e as indagações sobre os aspectos que transcendem a vivência do dia a dia. 


\section{(...)}

Depois encontrei meu pai, que me fez festa

e não estava doente e nem tinha morrido, por isso ria, os lábios de novo e a cara circulados de sangue,

caçava o que fazer pra gastar sua alegria:

onde está meu formão, minha vara de pescar, cadê minha binga, meu vidro de café?

Eu sempre sonho que uma coisa gera, nunca nada está morto.

O que não parece vivo, aduba.

O que não parece estático, espera.

(PRADO, 2015, p. 22)

O pai faz festa por não estar doente nem morto, enquanto podemos identificar que, em muitas salas de aula, os processos de ensino-aprendizagens percorrem um caminho que se distancia do riso, da alegria e da admiração, principalmente com formas de preencher a educação de explicações dissociadas de compreensões, essencialmente em seus anos iniciais, ocasionando, em instâncias diversificadas, a inexistência de movimento, ou um movimento em que o conteúdo é justificado pelo próprio conteúdo, sem adubar a vida pela compreensão das coisas mesmas, mas sim pelo distanciamento que os conceitos podem trazer pela superficialidade da simples explicação pela explicação.

\section{CONSIDERAÇÕES FINAIS}

Nossa viagem chega à estação das suspeitas diante de inúmeras perguntas sobre o futuro do ensino médio brasileiro em seu aspecto pedagógico, visto que em seu aspecto político, talvez, não reste dúvidas de que ela seguirá imbuída de características impositivas e centralizadoras por parte do Estado, com nuances de um processo democrático, mas que segue a estrutura do sistema maior, com interesses que estão inseridos nas bases de contextos políticos e econômicos.

A ausência, ainda, da BNCC constituem um nebuloso futuro sobre os processos de ensino-aprendizagens que se darão nas relações entre a escola, seu corpo docente e discente, 
além das relações destes com diretores e coordenadores. Nesse aspecto, os trilhos percorridos por nosso trem de ferro estarão concebidos sob o terreno das relações que o sistema socioeconômico permite e constrói por meio de suas contradições e crises que são próprias do sistema.

Diante desta "coisa mecânica" que pode se potencializar sob a rigidez da lei da "reforma" - ou seus enquadramentos com aparência de flexibilidade e autonomia para os educandos - na qual as escolas e suas relações intrínsecas podem se estabelecer, entende-se que o conceito de alteridade levinasiano pode constituir-se como uma ferramenta que humaniza as relações diretas entre educadores e educandos, além de concebê-los em comunhão diante das dinâmicas pedagógicas que, por ventura, se apresentem em formas da própria lei aqui tratada, ou em outras que virão. Ainda, para que haja um aspecto didático prático nos processos de ensino-aprendizagens, a poesia adeliana, permeada de sentimentos, sentidos e reverberações entre o simesmo e o Outro, permite que, diante das dinâmicas infinitas de percepções de $U m$ em conjunto e complemento com o Outro, um mirandum pedagógico esteja em constante proeminência sob as manifestações do "mundo do trabalho" e seus trilhos demasiadamente retilíneos e mecânicos.

\section{REFERÊNCIAS}

CERBONE, David R. Fenomenologia. Petrópolis-RJ: Editora Vozes, 2013.

HOHLFELDT, Antônio. BETT', Frei. MIRANDA, Ana. Org. Adélia Prado. Rio de Janeiro: Instituto Moreira Sales, 2000.

FISCHMANN, Roseli. Relevância da dimensão cultural na pesquisa educacional: Uma proposta de transversalidade. ECCOS, São Paulo, v. 7, n. 1, p. 41-56, jun. 2005.

JAEGER, Werner. Paideia - A formação do homem grego. São Paulo: Editora WMF Martins Fontes, 2013.

LE BRETON, David. Antropologia dos sentidos. Petrópolis - RJ: Vozes, 2016. 
LÉVINAS, Emmanuel. Entre Nós. Ensaios sobre alteridade. PetrópolisRJ: Vozes, 2005.

Humanismo do outro homem. 4. ed. Petrópolis-RJ: Vozes, 2012.

Totalidade e infinito. Tradução de José Pinto Ribeiro. Lisboa:

Edições 70, 1980.

MORAES, Maria Cândida. O paradigma educacional emergente. Campinas, SP: Papirus, 2012.

PESSOA, Fernando. Poesias. Porto Alegre: L\&PM, 2016.

PIEPER, Josef. Que é filosofar? São Paulo: Loyola, 2008.

PRADO, Adélia. Poesia reunida. Rio de Janeiro: Editora Record, 2015.

RICOEUR, Paul. O si-mesmo como um outro. Campinas: Papirus, 1991.

Percurso do reconhecimento. São Paulo: Loyola, 2006.

\section{Sobre o autor}

Professor da Educação Básica no estado do Tocantins. Graduado em Sociologia e Política pela Fundação Escola de Sociologia e Política da São Paulo (2011), com especialização em Filosofia contemporânea e História pela Universidade Metodista de São Paulo (2014) e mestrado em educação pela Universidade Metodista de São Paulo (2018). 